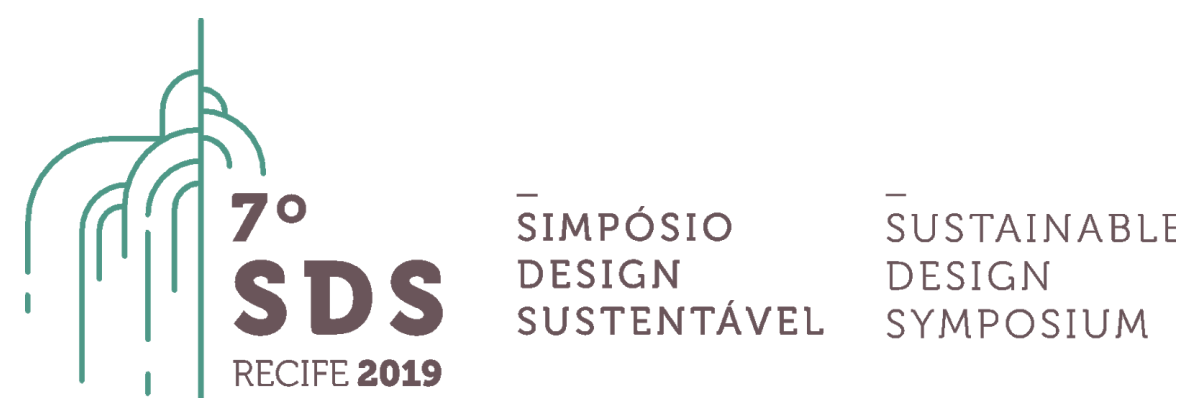

\title{
Tingimento Natural em Palha de Carnaúba: Relato de experiência no grupo Mulheres da Palha em Juazeiro do Norte - CE
}

\author{
Juliana Loss Justo', Saymo Venicio Sales Luna², Antônio Italcy de Oliveira Júnior ${ }^{3}$ \\ ${ }^{1}$ Universidade Federal do Cariri, juliana.loss@ufca.edu.br \\ ${ }^{2}$ Universidade Federal Rural de Pernambuco, saymon.luna@gmail.com \\ ${ }^{3}$ Universidade Federal de Pernambuco, antonioitalcy@hotmail.com
}

\begin{abstract}
Resumo. O presente artigo visa apresentar a experiência de uma oficina de tingimento natural realizada junto a estudantes do curso de design da Universidade <omitido para revisão cega> e as Mulheres da Palha, grupo de artesãs que trabalha com palha de carnaúba em Juazeiro do Norte. O processo utilizado pelo grupo utiliza substâncias claramente nocivas durante sua manipulação, que também impactam o ambiente após seu descarte. Na atividade foram utilizadas plantas encontradas na região para realização de experimentos, os quais foram percebidas alguns potenciais, mas também obstáculos até que se consiga a inserção do processo na rotina produtiva do grupo. Também destaca a importância de discutir a temática da sustentabilidade com estudantes e fazer esta aproximação com a comunidade do entorno de modo a fortalecer a formação destes projetistas.
\end{abstract}

Palavras chave. Artesanato, palha de carnaúba, tingimento natural.

\section{Introdução}

O artesanato em palha de carnaúba desenvolvido na cidade de Juazeiro do Norte - CE tem algumas características bem peculiares: a variedade e combinação de cores, a presença nas manifestações religiosas locais e a diversidade de tramas. Por ser um produto confeccionado com matéria prima de fonte renovável, utilizar de equipamentos e ferramentas simples e gerar autonomia financeira para diversas mulheres em situação de vulnerabilidade, o trançado em palha possui grande potencial de geração de renda com baixo impacto ambiental. Tendo grande parte de seu ciclo de vida percorrido de modo sustentável, é necessário lidar ainda com a problemática do tingimento dessa matéria prima, atualmente feito de modo bastante inseguro e com utilização de corantes sintéticos que liberam toxinas durante o processo de tintura das fibras, gerando efluentes que são descartados indiscriminadamente no meio ambiente.

Uma alternativa sustentável para o processo de tingimento é a utilização de materiais de origem natural para extração dos pigmentos. Segundo Fletcher e Grose (2011), o propósito dos adeptos à utilização de corantes naturais para o tingimento é não corroborar com os valores que $7^{\circ}$ 
as indústrias impõem, contudo, trabalhar dentro dos limites da natureza, adequando criatividade e prática de acordo com as necessidades.

Tendo como foco desenvolver alternativas sustentáveis para utilização de cores nestes produtos, no ano de 2017 foi proposto uma oficina experimental de tingimento com corantes naturais para um pequeno grupo de artesãs da palha da carnaúba - Mulheres da Palha. Buscou-se verificar cores e fixação de diferentes materiais naturais facilmente encontrados na região, conforme relatado por Luna et al. (2017), em detrimento aos materiais químicos, visando reduzir os riscos a saúde das artesãs no manejo e possivelmente gerar efluentes do processo de tinturaria com menor carga de poluição.

A atividade integrou o ciclo de uma disciplina de Ecodesign, ministrada na Universidade <omitido para revisão cega> por uma das autoras deste artigo. Deste modo, conseguiu-se fazer uma interessante e importante conexão entre as artesãs e os discentes da disciplina, contando ainda com a participação de dois egressos do curso de Design de Produto e de Engenharia Civil, os quais também participam deste relato e puderam dar suas contribuições técnicas nos processos, planejamento, execução e avaliação dos resultados da oficina realizada.

A respeito da disciplina, trata-se de uma modalidade recém institucionalizada na universidade, na qual é prevista a realização de atividades de extensão inseridas na dinâmica da disciplina com objetivo de estimular o cumprimento da determinação do Plano Nacional de Educação de 2014. Este prevê a integralização de ações de extensão em $10 \%$ de todos os currículos de ensino superior no país. A integração da universidade com a comunidade externa constitui, portanto, um caminho para cumprir a legislação brasileira e ao mesmo tempo um cenário de oportunidades para os cursos superiores de Design de buscarem soluções conjuntas para problemáticas reais. Como afirma Manzini (2008, p. 62) "o conjunto da sociedade contemporânea, em sua complexidade e contraditoriedade, pode ser visto como um imenso laboratório de ideias para a vida cotidiana, onde modos de ser e de fazer se desdobram em novas questões e respostas inéditas." O autor afirma ainda que é neste tipo de situação que surge a Inovação Social que, no nosso caso, é uma forma de solução para a problemática do tingimento da palha de carnaúba através de processos mais sustentáveis.

As artesãs envolvidas já haviam participado de um projeto de extensão com a docente e o designer que participaram da oficina e, portanto, já havia uma integração entre ambos, o que facilitou o desenvolvimento da atividade. Também os estudantes da disciplina já haviam conhecido as artesãs em outro momento, durante uma atividade na sede do grupo. Estas mulheres reúnem-se semanalmente para confeç̧ão de produtos em palha e distribuição em alguns canais de venda além de produção de encomendas. A necessidade de alternativas ao tingimento artificial havia sido levantada pelo grupo em momentos anteriores, já que um de seus principais compradores realiza controle rigoroso de qualidade, o que inclui o atendimento aos aspectos de sustentabilidade. Neste caso, o uso de palhas coloridas restringia-se apenas à cor verde clara e bege, já que são as duas opções naturalmente já disponíveis no material.

\section{Projeto Mulheres da Palha}

O grupo de artesãs que participou da oficina é atualmente formado por 3 membros, para as quais o trabalho com palha de carnaúba é sua principal fonte de renda. 0 grupo originou-se em torno de um projeto ${ }^{1}$ de extensão da Universidade, <omitido para revisão cega> que ganhou premiação em 2011 e trabalhou de modo contínuo com estas mulheres até começo de 2013. Tendo variado o número de participantes desde sua formação inicial, o grupo permanece em atividade até os dias atuais, produzindo e comercializando os produtos criados em parceria e aplicando os conhecimentos construídos ao longo da intervenção.

\footnotetext{
${ }^{1}$ Ver Geammal et al, 2012 para maiores detalhes sobre o projeto e o grupo.
} 
Durante o projeto participaram em diferentes momentos e de modo integrado estudantes e docente dos cursos de design, comunicação social/jornalismo, administração pública e psicologia. Neste período a sede do grupo passou por algumas reformas que possibilitaram a ocupação para produção, comercialização e armazenamento de insumos e produtos. Além disso, o valor da premiação permitiu o desenvolvimento e produção de material gráfico, como etiquetas, portfólio, compra de equipamentos e matérias primas. Também foi possível a concessão de bolsas aos estudantes que atuaram junto aos professores no planejamento e execução de oficinas, desenvolvimentos de produtos, participação em eventos e outras atividades, os quais, sempre que possível envolviam também as artesãs. Este envolvimento deve sempre ser o horizonte de qualquer ação de caráter extensionista:

Manter uma visão crítica diante das metodologias participativas na extensão universitária é central para não cair numa retórica que facilite a aprovação de projetos nesse campo, mas que não garanta nem uma efetiva participação dos interessados, tampouco a produção de um conhecimento emancipatório, adequado para esse tipo de objetivo (FORPROEX, 2012).

Tendo, portanto, a participação dos envolvidos em todos os níveis, é possível ainda analisar o tipo de trabalho desenvolvido junto a estas artesãs a partir dos tipos de intervenções listadas por Adélia Borges (2011), chegando à conclusão que foram executadas: melhorias de condições técnicas, uso de materiais locais, identidade e diversidade, construção de marcas, e ações combinadas. Vale salientar que em diferentes momentos ao longo da história destas mulheres, antes ou depois do projeto, também trabalharam como fornecedoras de técnicas e habilidades para produtos de outros designers, estilistas ou mesmo uma cachaçaria que utiliza o trançado para acabamento de suas garrafas.

As atividades realizadas em parceria com o grupo auxiliaram na melhoria da qualidade dos produtos e inserção deles em novos mercados. O cálculo adequado do custo/preço, ajustes de moldes e gabaritos, inserção de características locais e ampliação da cartela de produtos são alguns itens que podem ser citados. Como afirmado anteriormente, havia ainda uma lacuna no que diz respeito à melhoria dos processos de tingimento, tanto do ponto de vista da sustentabilidade, quando na qualidade das cores em si.

\section{Tingimento Natural}

O processo de tingimento utilizado pelo grupo e demais artesãs da palha da carnaúba em Juazeiro do Norte faz uso de corantes para tingimento de tecido comumente encontradas no comércio local, que deixa a desejar em relação a qualidade e variação de cores, além da fixação. Este grupo especificamente utiliza também, uma anilina química em pó adquirida por meio de compra online que resulta em tingimentos com qualidades melhores, mas é visivelmente nociva à saúde. Para Verissimo (p. 14, 2003), "os riscos toxicológicos de corantes sintéticos à saúde humana estão intrinsecamente relacionados ao modo e exposição, isto é, ingestão oral, sensibilidade da pele e sensibilidade das vias respiratórias". Participando do processo de tingimento, realizado através do cozimento da palha na água diluída com o corante, é possível sentir o cheiro forte e irritação nos olhos e na mucosa da boca, diante disto nota-se claramente que este processo não é salutar.

Os tingimentos naturais estão presentes no cotidiano das sociedades ao longo dos anos. Os mesmos têm sido objeto de estudo em diversos campos do meio científico na atualidade como, por exemplo, o design e a engenharia. Os primeiros registros da obtenção e utilização de corantes naturais ocorreu na China por volta de 2600 a.C. (PEZZOLO, 2007). Esses tingimentos, resultados da extração de pigmentos de cascas de árvores, folhas, flores e frutos dispostos na natureza, foram por muitos anos os únicos responsáveis por conferir cores às fibras naturais, fossem de origem vegetal ou animal. No entanto, com o advento dos corantes sintéticos, essas práticas 
foram caindo em desuso mesmo sabendo dos impactos negativos ao meio ambiente ocasionados pelos pigmentos artificiais.

Os conhecimentos e técnicas de tingimento natural foram resguardadas por artesãos e resgatada nos últimos tempos a partir de um novo olhar, mais sustentável, que a sociedade dispõe. A demanda por práticas sustentáveis que possam preservar recursos naturais e garantir a vida das gerações futuras fez com que as matérias primas utilizadas nos processos de tinturarias fossem repensadas, bem como os resíduos gerados nestes processos apresentassem menor potencial de poluição.

Este olhar para práticas tradicionais com a intenção de buscar processos mais sustentáveis passou pela suspeita de alguns observadores de que poderiam incorrer em um saudosismo improdutivo nos levando a buscar um modo de vida que não poderíamos mais praticar, alertou Manzini (2008). No entanto, o autor afirma que :

Olhando para esses casos e suas motivações com mais cuidado, é possível constatar claramente que nada poderia ser mais falso: o "passado" que emerge nesses casos é um recurso social e cultural extraordinário, absolutamente atualizado [...] representa a herança de conhecimento, padrões de comportamento e formas de organização que, à luz das atuais condições de existência e dos atuais problemas, podem representar um valioso material de construção para o futuro (CCSL, 2007 apud MANZINI, 208, p.66)

Desta forma, além de atender a requisitos sustentabilidade, o uso de corantes naturais para o tingimento da palha de carnaúba seria uma oportunidade de olhar para as plantas locais e valorizar capital territorial ${ }^{2}$ do Cariri. Esta relação perceptível entre o produto com a comunidade produtora e os recursos locais confere à esta produção um novo tipo de qualidade, cada vez mais desejada pelos consumidores, conforme afirma Krucken (2009).

Em países como o Brasil, que possuem clima tropical e extensão continental, apresentam ampla diversidade de sistemas florestais. Isto favorece para uma maior amplitude de paletas de cores e para a sustentabilidade dos tingimentos naturais, "tirando das nossas árvores, em suas flores, seus frutos, suas cascas e suas folhas, as mais variadas cores para aplicá-las no dia-a-dia da produção artesanal e industrial" (FERREIRA, 1998, p. 2).

Para Araújo (2006) os corantes naturais são substâncias coradas extraídas por processos físico-químicos (por exemplo, a dissolução, precipitação, etc) ou por processos bioquímicos (fermentação) de uma matéria-prima de origem animal ou vegetal. A mesma fonte relata ainda que estas substâncias devem ser solúveis em fases líquidas onde durante o processo de tingir os substratos possam ser submergidos.

\section{$4 \quad$ A Oficina}

Como dito, a oficina de tingimento fez parte da disciplina de Ecodesign, que por sua vez trabalhou as diferentes abordagens de design para sustentabilidade. Slow Design, Design Social, Crowd Design e Design de Serviços foram alguns dos temas discutidos em sala com os alunos. A oficina seria, portanto, uma atividade prática na qual os estudantes teriam a oportunidade de vivenciar diversos conceitos trabalhados no ambiente acadêmico e fortalecendo o processo de ensino aprendizagem.

Para o trabalho final da disciplina foi proposto o desenvolvimento de um produto pensado a partir de uma concepção mais sustentável do design dentro de um território. Para isso, tivemos

2"O conjunto dos elementos de que dispõe o território nos níveis material e imaterial, que podem constituir, em alguns aspectos, vantagens e, em outros, desvantagens" (Observatório Europeu Leader 1999, p.19, apud KRUCKEN 2009, p.34). 
alguns encontros na sede das Mulheres da Palha para integração dos participantes, conhecimento da técnica do trançado em si, discussão das necessidades e possibilidades e criação. Krucken (2017, p.329) reforça a "importância do trabalho conjunto, das colaborações, alianças, parcerias e redes, que são imprescindíveis para desenvolver projetos territoriais".

A conversa informal era o que regia esses encontros e à medida que as artesãs mostravam aos estudantes como se trança a palha, eles as provocavam com novas ideias de produtos que, dentro do possível, iam sendo concretizados naquele momento.

Já na oficina de tingimento, necessitou de uma organização mais estruturada, pois envolvia a necessidade de adquirir previamente as matérias primas que seriam utilizadas para a extração dos pigmentos, bem como a madeira que seria utilizada para o cozimento dos extratos - o grupo utiliza fogo à lenha improvisado para os tingimentos artificiais (Figura 1).

Figura 1 - Cozimento do Extrato de Açafrão

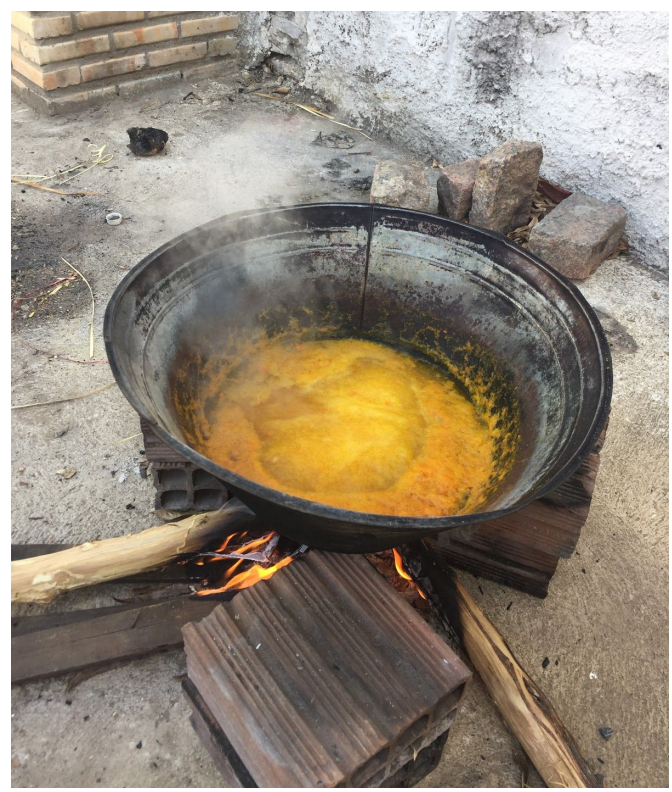

Fonte: os autores, 2017

A oficina foi dividida em três momentos onde inicialmente foi apresentado ao grupo (artesãs e alunos) os conceitos básicos sobre tingimento natural a partir do referencial utilizado para planejar a atividade, os materiais que seriam utilizados para os experimentos, que foram: beterraba, sementes de urucum, açafrão em pó e flor de hibisco. Na sequência, foi explanado as diferentes formas de extrair os pigmentos e as possibilidades de pigmentação a partir de outras matérias primas encontradas nas proximidades. É interessante perceber que a proposta de diálogo em grupo facilita a intervenção dos participantes e disto surgem ideias e novas possibilidades.

Por fim, realizamos com o grupo o processo experimental do tingimento em si, a partir da imersão dos olhos ${ }^{3}$ de palha nos extratos das plantas e água, que foram cozidos durante algum tempo. A este líquido foi adicionado de Alúmen de Potássio KAl(SO4)2 utilizado como mordente ${ }^{4}$ na atividade.

O primeiro teste realizado utilizou o açafrão previamente diluído e em um pouco de água. Para cocção da palha no corante foi utilizado um recipiente de zinco (figura 2) comum aos processos de tingimento feitos pelo grupo. De imediato foi possível observar a adesão da cor na palha, inclusive entre as partes que estavam amarradas em uma das extremidades.

\footnotetext{
${ }^{3}$ Após a separação das partes da palha as mesmas são agrupadas e amarradas por outra palha.

${ }^{4}$ Mordente é alguma substância utilizada durante o processo de tingimento que auxilia na fixação da cor.
} 
Figura 2 - cozimento da palha em bacia de zinco.

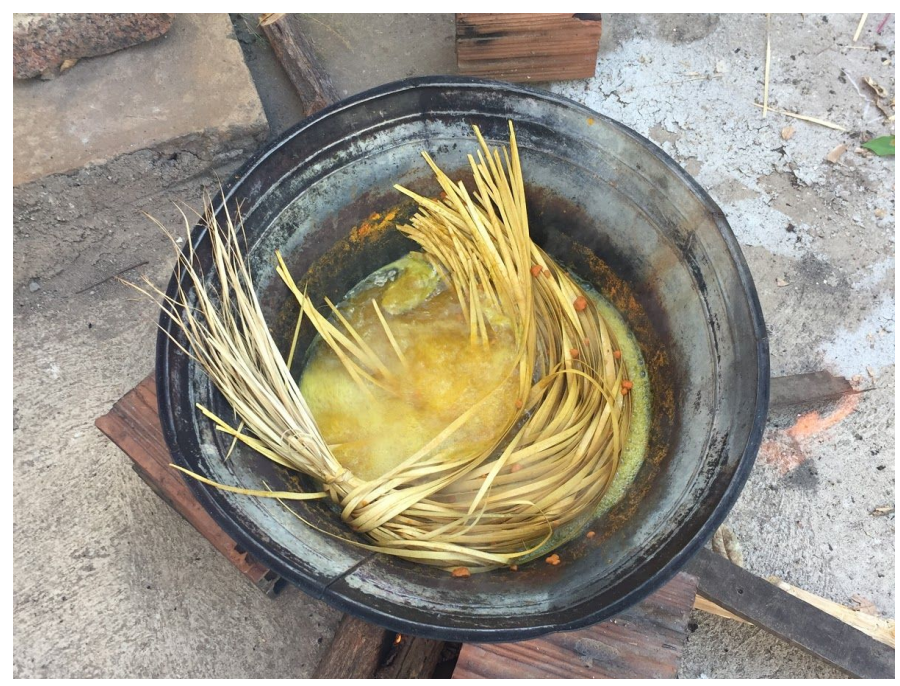

Fonte: os autores, 2017

Para o experimento seguinte realizamos a limpeza do recipiente (o que se repetiu a cada processo) a fim de retirar qualquer vestígio de tintura anterior e não confundir os resultados. A flor de hibisco foi adicionada à água na bacia na qual ficou um certo tempo de cozimento para que fosse possível extrair a cor da planta (figura 3) antes de adicionar a palha. Neste caso, como desconfiou-se após algum tempo do cozimento que poderia não haver fixação de cor neste processo, realizamos também o tingimento de um tecido para aproveitamento deste substrato. Já que o material é também utilizado pelas artesãs a coloração natural dos tecidos (figura 4), iria contribuir no processo de qualidade da produção do grupo.

Figura 3 - infusão das flores de hibisco

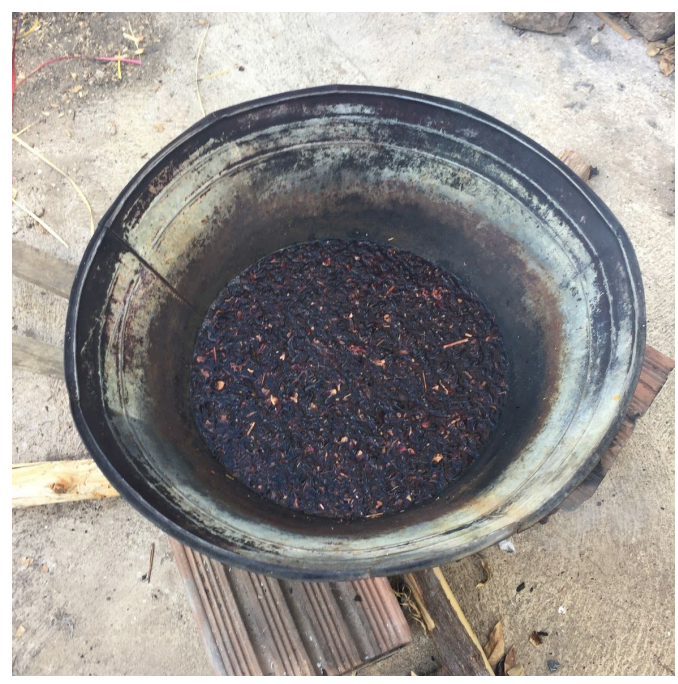

Fonte: os autores, 2017
Figura 4 - tingimento do tecido de algodão cru com flor de hibisco

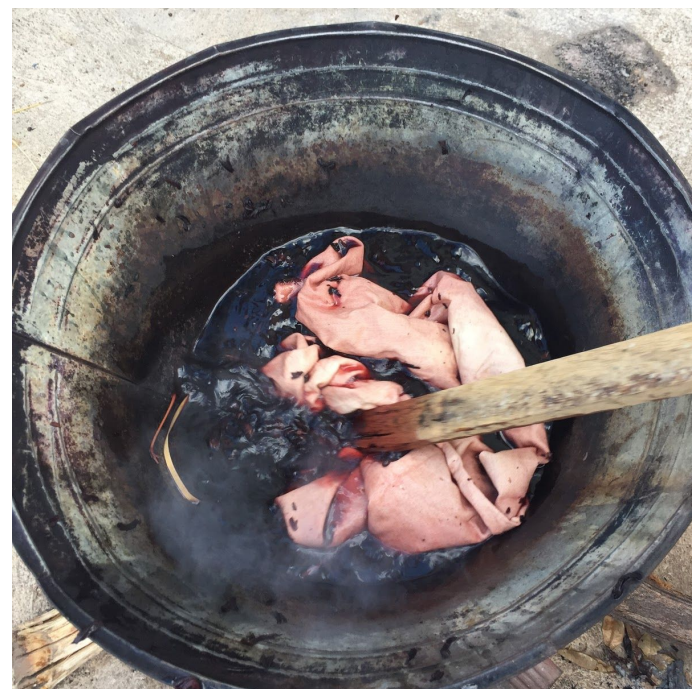

Fonte: os autores, 2017

Já para para uso da beterraba, a extração da cor foi feita a partir da mistura de pedaços da raiz com álcool no liquidificador. Em seguida, neste caso com maior cautela ainda, devido o uso de álcool, também foi realizado o cozimento da palha em panela de zinco. 
Por fim, foi realizado o experimento com o urucum que foi pilado (figura 5) antes de misturado à água. Aqui, a fim verificar uma variedade maior de processos, optamos por tingir uma peça já trançada (figura 6), deste modo seria possível verificar ocorrência de deformações ou coberturas defeituosas dentre as camadas sobrepostas de palha.

Figura 5 - preparo das sementes de urucum

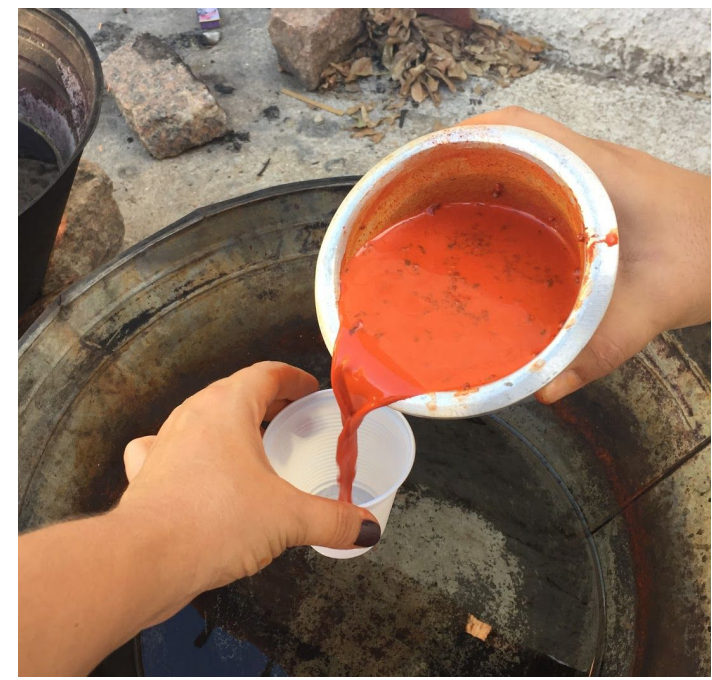

Fonte: os autores, 2017
Figura 6 - tingimento de uma peça de palha com sementes de urucum

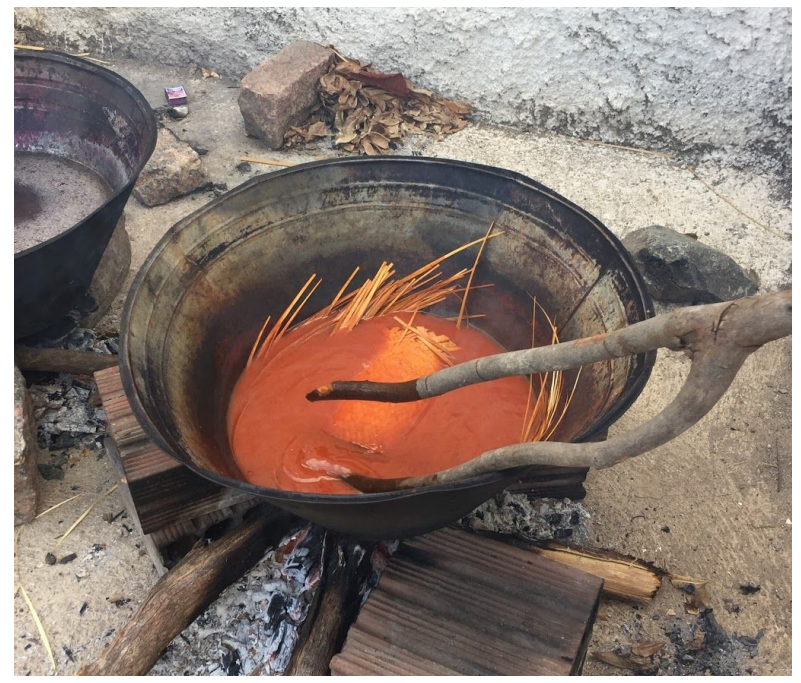

Fonte: os autores, 2017

No encerramento da atividade foi feita uma avaliação da oficina por parte de todos, tanto das questões técnicas quanto da metodologia em si. Alguns dos resultados discutidos neste momento podem ser verificados no tópico a seguir.

\section{$5 \quad$ Resultados Alcançados}

Por se tratar de um primeiro experimento, ficamos livre em relação aos processos o que, por um lado, conferiu dinamismo e liberdade à atividade, mas também deixou escapar aspectos que necessitam de um controle mais formal para uma investigação precisa da viabilidade do tingimento natural. Até mesmo durante o processo de escrita deste trabalho verificamos a falta de anotações mais detalhadas sobre os resultados, medidas dos insumos e preços para posterior cálculo de custos entre outros fatores necessários para que o tingimento natural venha de fato a ser efetivado na rotina do grupo.

Esta deficiência do processo pode e deve ser superado a partir de testes em laboratório, onde será possível ampliar a utilização dos extratos a serem utilizados, ajustar o modo de extração das cores para cada planta, verificar o tempo de cozimento necessário, experimentar outros mordentes, entre outros fatores que venham a aumentar a variedade de cores e também a qualidade do processo e do resultado final. Vale salientar que este controle deve ser feito sempre tendo em vista a realização do tingimento pelas artesãs e em seu ambiente e, portanto, mesmo aconteça no ambiente do laboratório acadêmico, a participação delas no processo seria de extrema importância.

Em relação ao resultado das cores (figura 7), observa-se uma diferença substancial em comparação ao uso de corantes químicos que resulta em cores extremamente vibrantes e contrastantes (figura 8). Os tons mais terrosos e pálidos alcançados não configuram em si um defeito ou problema a ser superado. A princípio, poderíamos supor que o público aceitaria este novo tipo de cartela, já que a palha "crua" é bem aceita pelo público consumidor, mas de todo modo, seria necessário um estudo prévio para confirmar ou refutar esta aceitação. 
Figura 7 - palhas tingidas com hibisco, beterraba, açafrão e urucum, respectivamente

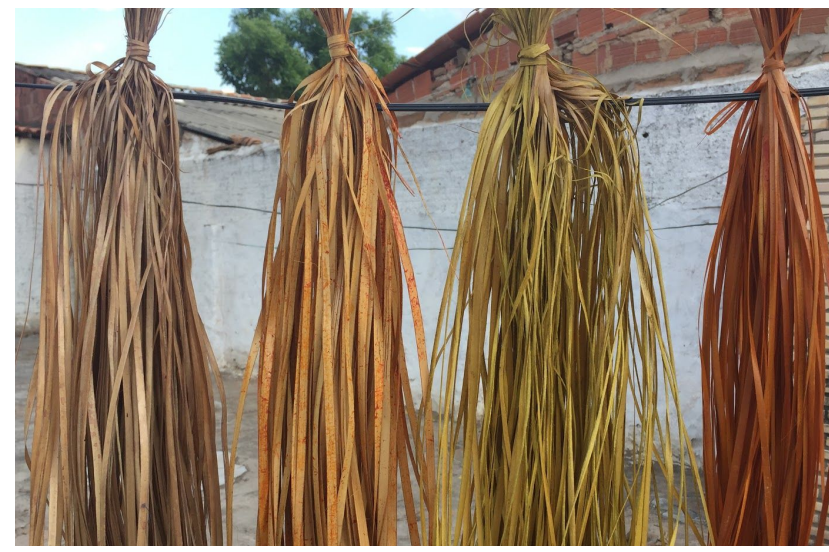

Fonte: os autores, 2017
Figura 8 - palhas tingidas com corantes químicos

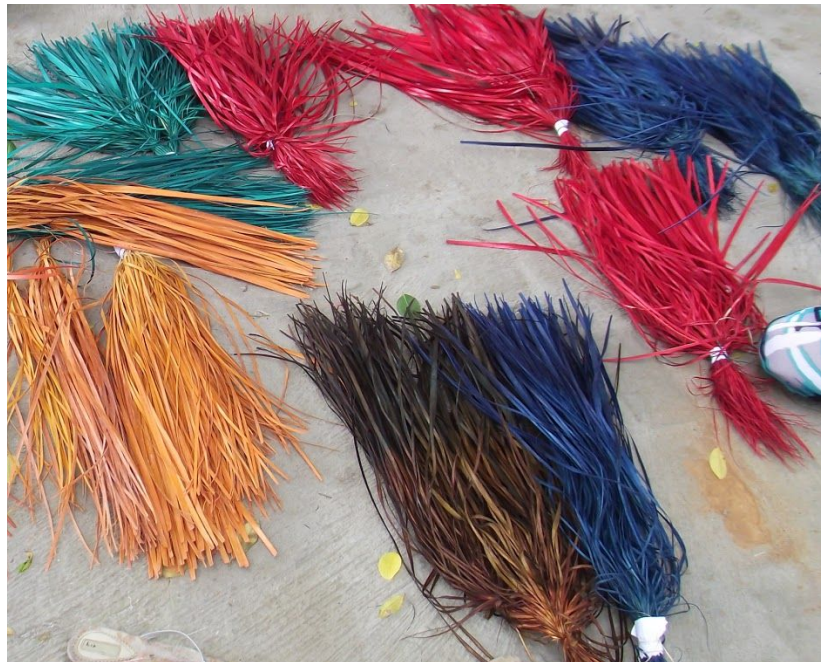

Fonte: os autores, 2012

Sabemos que historicamente a cor vibrante do artesanato em palha de carnaúba na região já constitui uma identidade absorvida pelo público consumidor. No entanto, não espera-se que esta característica permaneça estática, como bem já observou McCracken (2007) a respeito do caráter móvel do significado cultural dos artefatos. Portanto, o fato das cores do processo natural ser diferente do tradicional pode ser um aspecto positivo e um processo de ressignificação do artesanato.

Outra questão observada que necessita de maiores testes é a uniformidade da cor, pois em algumas foi percebido concentração do pigmento (figura 9), talvez por conta da diluição incompleta, talvez pela própria característica da palha, que possui uma cera em sua superfície que é inclusive aproveitada na confecção de produtos de limpeza, por exemplo. Este seria mais um aspecto a ser estudado para em seguida melhorado ou usado a favor do processo.

Figura 9 - palha com "falhas" na adesão da cor.

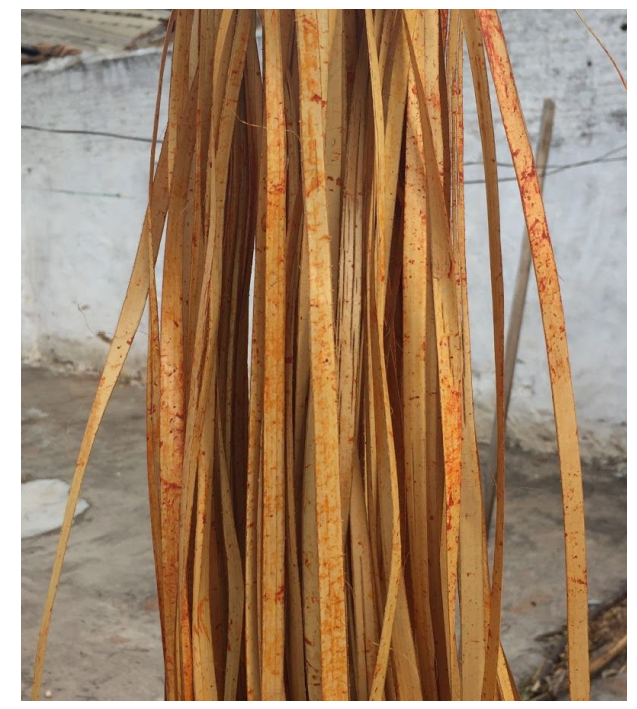

Fonte: os autores, 2017 
Como é possível observar, alguns pontos de cor deixaram a palha sem uniformidade, algo que não é incomum de acontecer mesmo nos corantes químicos, mas que neste processo ficou mais ressaltado.

Também não foram realizados testes para verificar a toxicidade e impacto na saúde no processo de tingimento e também dos efluentes. No entanto, no que diz respeito à sensibilidade das mucosas durante o manejo não verificamos nenhum incômodo, o que já é um indicativo de que ela deve ser menos agressiva que os corantes artificiais comprados comercialmente. Posteriormente será verificado se atendem aos parâmetros fisico-químicos exigidos pela resolução CONAMA 430/2011 que dispõe sobre condições e padrões de lançamentos de efluentes.

\section{Considerações finais}

A oficina de tingimento natural buscou integrar a comunidade de artesãs e acadêmico na busca de soluções ambientalmente viáveis para coloração da palha da carnaúba a partir da valorização da capital do território caririense. Trata-se de uma situação de enorme desafio, mas também na qual se percebe um grande potencial de desenvolvimento de processos sustentável nos diferentes pilares.

É importante frisar que os resultados ou dificuldades encontradas não se restringem apenas às questões técnicas trabalhadas, mas também na importância que este tipo de encontro possui para todos os participantes. Assim, em relação à disciplina, na avaliação dos estudantes foi possível confirmar a relevância da realização de atividades junto ao grupo. A conversa com pessoas que vivenciam outras realidades, os desafios impostos pelo trabalho manual, as possibilidades de construção a partir de uma prática, a experimentação e busca de soluções em conjunto configuram importantes ferramentas para a formação de designers qualificados e cidadãos mais conectados com sua comunidade.

Para as artesãs é preciso ainda ter um cuidado em relação ao que se pode afirmar de ganhos para o grupo. Sabemos que a atividade gera uma expectativa para a solução de um problema bem pertinente e que impacta diretamente a saúde delas e que a Universidade deve cumprir seu papel social de resolver as questões da sociedade. Por outro lado, este processo deve ser realizado de modo participativo, tendo em vista que sabemos que o uso de corantes naturais constituirá uma quebra de paradigmas para o grupo e, portanto, o desenvolvimento conjunto aumentará as chances da implementação.

\section{Referências}

ARAÚJO, M. E. M. de. Corantes naturais para têxteis: da Antiguidade aos tempos modernos. Conservar Património, n. 3-4, p. 39-51, diciembre, 2006. 2011.

BORGES, A.. Design + artesanato: o caminho brasileiro. São Paulo: Editora Terceiro Nome.

FERREIRA, E. L. Corantes naturais da flora brasileira: guia prático de tingimento com plantas. Curitiba: Optagraf Editora e Gráfica Ltda, 1998.

FLETCHER, K.; GROSE, L. Moda e sustentabilidade: design para a mudança. São Paulo: Editora Senac São Paulo, 2011.

FORPROEX. Política Nacional de Extensão Universitária. Recife: UFPE, 2013.

KRUCKEN, L. Design e território: valorização de identidades e produtos locais. São Paulo: Studio Nobel, 2009.

KRUCKEN, Lia. Ecovisões sobre Design e Território. In: Ecovisões projetuais : pesquisas em 
design e sustentabilidade no Brasil [livro eletrônico] /OLIVEIRA, Alfredo Jefferson; FANZATO, Carlo : DEL GAUDIO, Chiara - São Paulo : Blucher, 2017.

LUNA, S. V. S.; OLIVEIRA JÚNIOR, A. I. de; SILVA, C. R. F. Tingimentos naturais na fibra de bananeira: uma proposta sustentável para o artesanato do cariri cearense. Ciência e Sustentabilidade, v. 3, n.o 2, p. 46-63, jul/dez, 2017.

MANZINI, Ezio. Design para inovação social: Comunidades Criativas, organizações colaborativas e novas redes projetuais. Rio de Janeiro: E-papers, 2008.

MCCRACKEN, Grant. Cultura e Consumo: uma explicação teórica da estrutura e do movimento do significado cultural dos bens de consumo. RAE - Revista de Administração de Empresas, vol. 47, n. 1, jan-mar 2007

PEZZOLO, D. B. Tecidos: história, tramas e usos. São Paulo: Editora Senac São Paulo, 2007.

VERÍSSIMO, S. A. Extração, caracterização e aplicação do corante de urucum (Bixa orellana L.) no tingimento de fibras naturais. 2003. Dissertação de Mestrado. Universidade Federal do Rio Grande do Norte. 